\title{
Universiteit
}

Leiden

The Netherlands

\section{Design, construction, and biological testing of an implantable porous trilayer scaffold for repairing osteoarthritic cartilage}

Campos, Y.; Sola, F.J.; Almirall, A.; Fuentes, G.; Eich, C.; Que, I.; ... ; Cruz, L.J.

\section{Citation}

Campos, Y., Sola, F. J., Almirall, A., Fuentes, G., Eich, C., Que, I., ... Cruz, L. J. (2019). Design, construction, and biological testing of an implantable porous trilayer scaffold for repairing osteoarthritic cartilage. Journal Of Tissue Engineering And Regenerative Medicine. doi:10.1002/term.3001

Version: $\quad$ Not Applicable (or Unknown)

License: $\quad$ Leiden University Non-exclusive license

Downloaded from: https://hdl.handle.net/1887/121576

Note: To cite this publication please use the final published version (if applicable). 


\section{Design, construction and biological testing of an implantable porous trilayer scaffold for repairing osteoarthritic cartilage}

Yaima Campos, ${ }^{a, b}$ Francisco J. Sola, ${ }^{b}$ Amisel Almirall, ${ }^{b, c}$ Gastón Fuentes, ${ }^{a, b, c, d}$ Christina Eich, ${ }^{a}$ Ivo Que, ${ }^{a}$ Alan Chan, ${ }^{e}$ Eric Kaijzel, ${ }^{a}$ Yasuhiko Tabata, ${ }^{c}$ Luis Quintanilla, ${ }^{d}$ José C. Rodríguez-Cabello, ${ }^{d}$ and Luis J. Cruz, ${ }^{a}$ *

a Translational Nanobiomaterials and Imaging, Department of Radiology, Bldg. 2, k4-44, Leiden University Medical Centre, Albinusdreef 2, 2333ZA Leiden, The Netherlands

${ }^{\mathrm{b}}$ Biomaterials Center, University of Havana, Avenida Universidad entre G y Ronda, Vedado, Plaza, CP 10400, La Habana, Cuba

${ }^{\mathrm{c}}$ Laboratory of Biomaterials, Department of Regeneration Science and Engineering, Institute for Frontier Life and Medical Sciences, Kyoto University, 53 Kawara-cho Shogoin, Sakyo-ku, Kyoto 6068507, Japan

d Bioforge Lab, Campus Miguel Delibes, CIBER-BBN, Universidad de Valladolid, Edificio LUCIA, Paseo Belén 19, 47011, Valladolid, Spain

e Percuros B.V., Zernikedreef 8, 2333 CL Leiden, The Netherlands.

Dr. Luis J. Cruz

Professor (Assistant)

Translational Nanomedicine and Imaging Group, Department of Radiology, C2-S-room 187 Leiden University Medical Center, Albinusdreef 2

2333 ZA Leiden, The Netherlands

Tel: +31 715265764,31684622441

Email: 1.j.cruz ricondo@,lumc.nl

KEYWORDS: Articular, Cartilage, Tissue Engineering, Trilayer Scaffolds, Implants. 


\begin{abstract}
Various tissue engineering systems for cartilage repair have been designed and tested over the past two decades, leading to the development of many promising cartilage grafts. However, no one has yet succeeded in devising an optimal system to restore damaged articular cartilage. Here, the design, assembly and biological testing of a porous, chitosan/collagen-based scaffold as an implant to repair damaged articular cartilage is reported. Its gradient composition and tri- layer structure mimic variations in natural cartilage tissue. One of its layers includes hydroxyapatite, a bioactive component that facilitates the integration of growing tissue on local bone in the target area after scaffold implantation. The scaffold was evaluated for surface morphology; rheological performance (storage, loss, complex and timerelaxation moduli at $1 \mathrm{kHz}$ ); physiological stability; in vitro activity and cytotoxicity (on a human chondrocyte $\mathrm{C} 28$ cell line); and in vivo performance (tissue growth and biodegradability), in a murine model of osteoarthritis. The scaffold was shown to be mechanically resistant and non-cytotoxic; favored tissue growth in vivo; and remained stable for 35 days post-implantation in mice. These encouraging results highlight the potential of this porous chitosan/collagen scaffold for clinical applications in cartilage tissue engineering.
\end{abstract}




\section{INTRODUCTION}

Articular cartilage protects the end of bones, helping to transfer the load between adjacent bones with a very low coefficient of friction. It provides a frictionless support surface and transmits tensile, compression and shear forces (Hunziker, 2002). Articular cartilage is avascular and contains very few cells (only $5 \%$ by weight). These cells, most of which are chondrocytes, are situated within an extracellular matrix of collagen and proteoglycans. The lack of lymphatic and blood vessels in articular cartilage and its low cell population makes migration of chondrocytes to damaged areas - and therefore, tissue repair - both slow and difficult (Hunziker, 2002; Secretan et al., 2010).

There are various causes of damage to articular cartilage, all of which have debilitating clinical and social effects on patients and limit healthcare resources (Hunziker, 2002). Furthermore, due to an ageing global population, the frequency of osteoarthritis (OA) - and consequently, its social effects - are set to rise. $\mathrm{OA}$ is not only characterized by damage to the cartilage, but also by weakening of the muscles, inflammation of the tendon and synovial tissue, and changes in the subchondral bone, which plays an important role in the pathogenesis of OA. Palliative techniques have been applied to relieve pain, and non-invasive techniques have been developed to improve function and reduce severe injuries; these methods vary widely in their efficacy (Hayami, 2008). Generally, treatment begins with specific anesthetics and anti-inflammatories (Hochberg et al., 1995). However, these are limited by variability in patient response, secondary effects and a lack of data on therapeutic efficacy (Zhang et al., 2008). Shortterm treatments such as topical agents, intra-articular corticosteroid injections (Kon et al., 2011; Østergaard \& Halberg, 1998), or arthroscopic chondroplasty, in which cartilage fragments are extracted, can also have negative effects for knee structure, as has been reported (Bartels et al., 2007). These are all short-term treatments and leave patients with some degree of disability (Bedi et al., 2010). Moreover, there are discrepancy on the reports regards the effectiveness of using glucosamine or chondroitin sulfate for management of pain due to articular cartilage degeneration and OA (Clegg et al., 2006). Diverse clinical interventions have been employed for cartilage repair, including arthroscopy, spinal cord stimulation, autografts, allografts, autologous chondrocyte implantation and injection of hyaluronic acid (Thier et al., 2017). Another technique that has been explored is the use of microfractures, in which subchondral bone is deliberately broken to induce migration of stem cells to the damaged area and stimulate growth of fibrocartilage (Bedi et al., 2010). However, the tissue generated is inferior to native cartilage (Chung \& Burdick, 2008). Another option, used in severe OA, is joint replacement. However, given that it leads to functional limitations, even for sedentary patients, it is generally only applicable to seniors (Bedi et al., 2010). Given the aforementioned shortcomings, there remains a pressing need for new and effective methods for cartilage repair.

A promising alternative to the methods mentioned above is the tissue engineering — namely, culturing cells ex vivo onto a scaffold by using growth factors, and then surgically implanting the pre-loaded scaffold into the patient's affected joint to initiate tissue growth in situ. This approach requires scaffolds 
that are biocompatible and allow cellular adhesion, growth and proliferation, remaining stable for a long period of time (i.e. several weeks at least) at the implantation site. The past 20 years has seen major advances in tissue engineering based on judicious combinations of mechanically suitable scaffolds, cells and growth factors.

Bioactive materials such as hydroxyapatite, $\alpha$ - and $\beta$-tricalcium phosphate, and Bioglass ${ }^{\circledR}$ are osteoconductive: they can bind to natural bone to form a layer of apatite (Hench, 1998; Kokubo, 1991; Neo et al., 1992). However, to be osteoinductive, most materials require the addition of osteoinductive agents, such as bone morphogenetic proteins (BMPs). Nonetheless some calcium phosphate biomaterials are inherently osteoinductive due to their particular porous structure (Ripamonti, 1996; Z. Yang et al., 1996; H. Yuan et al., 2001; Huipin Yuan et al., 2000). Accordingly, they induce bone tissue formation without the need of addition osteogenic cells or BMPs. The growth of bone during their implantation in some soft tissue gives evidence of bone induction.

Here, the design, assembly and biological testing of a porous, chitosan/collagen-based scaffold as an implant to repair damaged articular cartilage is reported. Its gradient composition and trilayer structure is aimed to mimic variations in natural cartilage tissue. One of its layers includes a bioactive component (hydroxyapatite) that facilitates integration local bone in the target area after scaffold implantation. The essential condition for this trilayer scaffold, once implanted, to bond/bind with the cartilage calcified zone is the formation of a surface apatite layer in situ. The scaffold was evaluated for surface morphology; dynamic mechanical performance (storage, loss, complex and time-relaxation moduli at 1 $\mathrm{kHz}$ ); physiological stability; in vitro activity and cytotoxicity (human chondrocyte $\mathrm{C} 28$ cell line); and in vivo performance for repair (tissue growth and biodegradability), in a murine model with induced osteoarthritis.

\section{EXPERIMENTAL SECTION}

All chemicals were purchased from Sigma-Aldrich Co. (Madrid, Spain, Sao Carlos, Brazil and Leiden, The Netherlands) were of analytical grade and used as received.

Hydroxyapatite (HAP). HAP $\left(\mathrm{Ca}_{10}\left(\mathrm{PO}_{4}\right)_{6}(\mathrm{OH})_{2}\right)$ was obtained by dropwise addition of aq. phosphoric acid $(250 \mathrm{~mL}, 0.4 \mathrm{~mol} / \mathrm{L})$ into a suspension of calcium oxide in bi-distilled water $(250 \mathrm{~mL}, \approx 0.5 \mathrm{~mol} / \mathrm{L})$ under stirring. The reaction $\mathrm{pH}$ was monitored until it reached $7.2 \pm 0.1$, at which point the resulting solid precipitate was left overnight in the reaction flask without stirring and washed several times with bidistilled water. It was then oven-dried at $105^{\circ} \mathrm{C}$ for $24 \mathrm{~h}$, heated to $1000^{\circ} \mathrm{C}$ for $3 \mathrm{~h}$ and finally, milled down to a particle size of $160 \mu \mathrm{m}$ (Ślósarczyk et al., 2005).

Polymer solutions. Aqueous solutions $(2 \% \mathrm{w} / \mathrm{v})$ of collagen (type I COL, bovine collagen fibers, commercial grade, Brazil), and of chitosan (CHI) were prepared in bi-distilled water. To this end, $2 \mathrm{~g}$ of either polymer was dissolved in $100 \mathrm{~mL}$ of distilled water and stirred for 24 hours with a magnetic stirrer. Then, $1 \mathrm{~mL}$ of acetic acid $(1 \% \mathrm{v} / \mathrm{v})$ was added and the solution was left to stir for another $24 \mathrm{~h}$. 
Scaffold design and fabrication. The trilayer scaffold was prepared according to the procedure summarized in Figure S1 to mimic the structure of natural cartilage tissue. Briefly, to obtain the calcifiedlayer (C-layer) suspension, equivalent volumes of $2 \%$ aq. chitosan solution and $2 \%$ aq. collagen solution were mixed under stirring (5000 rpm; Ultra-Turrax ${ }^{\circledR}$ stirrer). Then, $10 \mu \mathrm{L}$ of Tween 80 per mL of layer suspension and a $2 \% \mathrm{w} / \mathrm{v}$ of hydroxyapatite were added. Stirring was maintained for 30 minutes and 16 $\mu \mathrm{L}$ of $1 \mathrm{M} \mathrm{NaOH}$ per $\mathrm{mL}$ layer suspension was added to neutralize the acetic acid. The mixture was poured into molds, and then frozen at $-80^{\circ} \mathrm{C}$ for $30 \mathrm{~min}$. The intermediate layer (I-layer) suspension was obtained using the same procedure, except that hydroxyapatite was omitted. The I-layer suspension was poured over the C-layer in the molds, and the resulting bilayer was frozen at $-80{ }^{\circ} \mathrm{C}$ for $30 \mathrm{~min}$. Finally, the top layer (T-layer) suspension was obtained using the same procedure as for the I-layer, except that a 3:1 (chitosan/collagen) volume ratio was used. The T-layer suspension was poured on top of the I-layer in the frozen bilayer, and the resulting trilayer structure was frozen at $-80{ }^{\circ} \mathrm{C}$ for $30 \mathrm{~min}$. Finally, the three-layer scaffold was freeze-dried in an Alpha 1-4 LD plus freeze-dryer (Martin Christ; Osterode am Harz, Germany). In the samples for in vivo study NIR4 dye (IR-780 Iodide) purchased from SigmaAldrich (Zwijndrecht, The Netherlands) was used. A $10 \mathrm{mg} / \mathrm{mL}$ solution of NIR4 dye (IR-780 Iodide) was prepared and $50 \mu \mathrm{L}$ were added to the mixture of each layer.

\section{Physico-chemical characterization of scaffolds}

Scanning Electronic Microscopy (SEM). Surface morphology, bioactivity and cellular adhesion efficiency of the scaffolds was evaluated by SEM using a NanoSEM 200 microscope (FEI, Japan). The materials were coated with an ultrathin layer $(300 \AA)$ of $\mathrm{Pd} / \mathrm{Pt}$ in an ion sputter coater (Cressington 208HR, United Kingdom). The surface morphology was studied by image analysis before the other tests were performed.

Micro Computed Tomography (micro-CT). Scaffold samples were scanned with the high resolution microtomography Skyscan 1076 (Bruker Micro-CT, Belgium) at a voltage of $40 \mathrm{kV}$, current of $250 \mu \mathrm{A}$ and using an aluminum filter of $0.5 \mathrm{~mm}$. Each sample was rotated by $180^{\circ}$ with a rotation step of $0.8^{\circ}$ according to the following set up: average frame of 4, nominal resolution $9-\mu \mathrm{m}$. The acquired images were reconstructed by the NRecon software (1.6.8.0) with corrections for alignment beam hardening and ring artefact reduction, and 3D models were created to allow visualizations of the samples in space (Cyttron Visualization Platform (LUMC, Leiden, The Netherlands).

Simulated biological fluid (SBF). SBF is a solution that contains an ionic concentration (Table 1) similar to that of human blood plasma but that lacks proteins. It is buffered with tris-hydroxymethyl aminomethane $(50 \mathrm{mM})$ and hydrochloric acid $(45 \mathrm{mM})$ at $36.5^{\circ} \mathrm{C}$ (Table 1) (Kokubo \& Takadama, 2006). 


\begin{tabular}{lll}
\hline Ion & Human plasma $(\mathrm{mmol} / \mathrm{L})$ & $\mathrm{SBF}(\mathrm{mmol} / \mathrm{L})$ \\
\hline $\mathrm{Na}^{+}$ & 142.0 & 142.0 \\
$\mathrm{~K}^{+}$ & 5.0 & 5.0 \\
$\mathrm{Mg}^{2+}$ & 1.5 & 1.5 \\
$\mathrm{Ca}^{2+}$ & 2.5 & 2.5 \\
$\mathrm{Cl}^{-}$ & 103.0 & 147.8 \\
$\mathrm{HCO}_{3}{ }^{-}$ & 27.0 & 4.2 \\
$\mathrm{HPO}_{4}{ }^{2-}$ & 1.0 & 1.0 \\
$\mathrm{SO}_{4}{ }^{2-}$ & 0.5 & 0.5 \\
\hline
\end{tabular}

Table 1. Concentrations of ions in human plasma and in SBF

Calcified layer bioactivity in SBF. The bioactivity of the scaffold in SBF was assessed through an immersion test performed in triplicate. Scaffold samples $\left(27 \mathrm{~mm}^{3}\right.$ cubes, with the calcified layer up) were immersed in SBF at a concentration of $10 \mathrm{mg} / \mathrm{mL}$ and removed from solution at 3, 7, 14 or 28 days. The isolated samples were washed with deionized water, dried at room temperature in a desiccator until reaching constant mass, and finally, their surface morphology was analyzed by SEM (Kokubo \& Takadama, 2006).

Cell-seeding efficiency. The cell seeding efficiency was evaluated by two methods: static surface seeding and cell suspension injection. In both cases, a density of $1 \times 10^{6}$ cells per scaffold (dimensions: 3 $\mathrm{mm} \times 3 \mathrm{~mm}$ ) was used. In the first method, $100 \mu \mathrm{L}$ of cell suspension with DMEM was placed onto the scaffold and the resulting system was incubated at $37^{\circ} \mathrm{C}$ and $5 \%(\mathrm{v} / \mathrm{v}) \mathrm{CO}_{2}$ for 3 hours. After that time, the pre-loaded scaffolds were immersed in DMEM as described elsewhere (Blum et al., 2004; Niemeyer et al., 2004; O'Brien et al., 2005). In the second method, $100 \mu \mathrm{L}$ of the cell suspension was injected by syringe (24-gauge needle) into the scaffold center, as reported elsewhere (Hofmann et al., 2003; Honda et al., 2004). After 3 hours of incubation, the pre-loaded scaffolds were immersed in DMEM as mentioned above. The distribution of chondrocytes within each sample was checked by cutting the scaffolds in slices (thickness: $10 \mu \mathrm{m}$ ), and then staining the cells with DAPI (Sigma-Aldrich) and treating them with the LIVE/DEAD ${ }^{\circledR}$ (Molecular Probes) assay for Confocal Microscopy (Leica TCS SP5).

\section{In vitro cell viability}

Viability assay. The suitability of the scaffolds for the culture of immortalized human chondrocytes (C28 cell line) (Goldring et al., 1994) was studied. Briefly, $3 \times 10^{4} \mathrm{C}-28$ human chondrocytes per well were seeded on the top of one scaffold sample ( $3 \mathrm{~mm}$ width and length $\mathrm{x} 1 \mathrm{~mm}$ height) with DMEM in a 48well plate. The scaffold samples were removed after 3 days, 7 days, 10 days or 14 days of seeding, and then assessed using a Calcein-AM/ethidium homodimer-1 (EthD-1) LIVE/DEAD ${ }^{\circledR}$ assay kit, according to the manufacturer's instructions. Specifically, the isolated pre-loaded samples were washed with PBS, treated with the assay kit, kept in darkness for 30 minutes and finally, studied by confocal microscopy. 
In the LIVE/DEAD ${ }^{\circledR}$ assay, living cells are stained green whereas dead cells are stained red (Tawakoli et al., 2013).

MTS assay. To further corroborate the cell viability results, an MTS assay was performed. This is a colorimetric technique in which in the presence of phenazine methosulfate (PMS), the (3-(4,5dimethylthiazol-2-yl)-5-(3-carboxymethoxyphenyl)-2-(4-sulfophenyl)-2H-tetrazolium) produces a formazan product that has an absorbance maximum at $490 \mathrm{~nm}$ in PBS. Scaffold samples with dimensions like viability assay were loaded with C-28 human chondrocytes (density: $1 \times 10^{4}$ per well; $500 \mu \mathrm{L}$ of cell suspension), and then culture for 3, 7, 10 or 14 days. At each time point, cells and scaffold were incubated in MTS solution in darkness for 3 hours, then $100 \mu \mathrm{L}$ of the supernatant solution was extracted to a 96well plate for reading into a tunable, spectrophotometric microplate reader (VersaMax, Pennsylvania, USA) (Program Softmax Pro) and the absorbance $(\lambda=490 \mathrm{~nm})$ was measured.

Osteogenic potential of the scaffold calcified layer. The osteogenic potential of the layer that has hydroxyapatite for the culture of osteoblasts differentiated from murine preosteoblastic KS483 cell line (van der Horst et al., 2002) was studied. Briefly, $3 \times 10^{4}$ cells per well were seeded on the top of one scaffold sample (3 mm width and length $x 1 \mathrm{~mm}$ height) with $\alpha \mathrm{MEM}$ in a 48 -well plate. The scaffold samples were removed after 3 days, 7 days, 10 days or 14 days of seeding, and then assessed using a Calcein-AM/ethidium homodimer-1 (EthD-1) LIVE/DEAD ${ }^{\circledR}$ assay kit, according to the manufacturer's instructions. Specifically, the isolated pre-loaded samples were washed with PBS, treated with the assay kit, kept in darkness for 30 minutes and finally, studied by confocal microscopy. In the LIVE/DEAD ${ }^{\circledR}$ assay, living cells are stained green whereas dead cells are stained red (Tawakoli et al., 2013).

Rheological properties. To evaluate the mechanical properties of the scaffold, were subjected to rheological experiments using a strain-controlled AR-2000ex rheometer (TA Instruments, Newcastle, Delaware, USA) was done. Before testing, each sample was submerged in water at $37^{\circ} \mathrm{C}$ for 15 min to achieve complete swelling. The swollen cylindrical scaffolds were then placed between parallel plates of non-porous stainless steel (diameter $=8 \mathrm{~mm}$ ). A sufficient normal force of approximately $0.2 \mathrm{~N}$, to prevent slippage was applied. A gap larger than $1000 \mu \mathrm{m}$ was always reached after the sample relaxed to equilibrium. Several oscillatory measurements have been made in a shear deformation mode. First of all, the range of the deformation amplitudes for which the scaffolds have a linear region of viscoelasticity has been determined. Based on this linear range, a dynamic strain sweep was performed at $1 \mathrm{~Hz}$ with oscillation amplitudes between 0.01 and $10 \%$, in order to measure the shear dynamic module as a function of the sample's deformation.

Dynamic frequency sweep tests were also performed to obtain the dependence between the shear dynamic modulus and the loss factor. For this reason, a voltage that was within the linear region of the scaffold was set, and a frequency sweep was carried out between 0.01 and $10 \mathrm{~Hz}$. Finally, a stress relaxation test was carried out to determine the transient evolution of the relaxation module, which must be coincident with that of the native tissue, since this behavior directly influences on the load transfer 
(Gonzalez de Torre et al., 2014; Mow et al., 1984).

Through the rheological measurements, the storage module, or modulus of elasticity $\left(\mathrm{G}^{\prime}\right)$, and the loss modulus, or viscosity module $\left(\mathrm{G}^{\prime \prime}\right)$, are obtained as a function of the voltage or frequency at a fixed temperature. The magnitude of the complex modulus, or dynamic shear modulus $\left(\left|G^{*}\right|^{2}=\left(G^{\prime}\right)^{2}+\left(G^{\prime \prime}\right)^{2}\right)$, and the loss factor $\left(\tan \delta=\mathrm{G}^{\prime \prime} / \mathrm{G}^{\prime}\right.$, where $\delta$ is the phase angle between the applied stimulus and the corresponding response) are obtained. In addition, the transient evolution of the relaxation module, $G(t)$ (J. L. Vanderhooft et al., 2009) is recorded.

Swelling test. For the swelling test scaffolds samples $(3 \mathrm{~mm} \times 3 \mathrm{~mm})$ were immersed in $10 \mathrm{~mL}$ of PBS at $37^{\circ} \mathrm{C}$. Each experiment was run in triplicate. The samples were removed every 5 minutes and weighed until a constant weight value was observed. The PBS uptake (U) in the scaffolds was calculated by the following equation:

$U(\%)=\frac{W_{s}-W_{d}}{W_{d}} \times 100$

where $\mathrm{W}_{\mathrm{d}}$ is the weight of the dry scaffold before start the swelling process and $\mathrm{W}_{\mathrm{s}}$ is the weight of the swollen scaffold.

In vitro enzymatic degradation. The enzymatic degradation of the scaffold was carried out in a collagenase solution. Scaffold samples $\left(27 \mathrm{~mm}^{3}\right.$ cubes $)$ were immersed into a solution of PBS with collagenase (type 1A Sigma) at a concentration of $370 \mathrm{ng} / \mathrm{mL}$ collagenase $1 \mathrm{~A}$, or into a solution of PBS alone (as control). The samples were kept under stirring at $80 \mathrm{rpm}$ at $37^{\circ} \mathrm{C}$ and each solution was replaced every 3 days. Scaffolds were removed at day 1, 3, 7, 14, 21 or 28, dried at room temperature, and then further dried in a desiccator until reaching a constant weight. The remaining weight $\left(\mathrm{W}_{\mathrm{r}}\right)$ and the soluble fraction (expressed as a percentage) of the scaffolds are defined by the following equations:

$W_{r}(\%)=\frac{W_{i}}{W_{d}} \times 100$

Soluble fraction $(\%)=\frac{W_{d}-W_{i}}{W_{d}} \times 100$

where $\mathrm{W}_{\mathrm{i}}$ is the weight of dry scaffold after swelling.

\section{In vivo study}

Animal model. The in vivo study was performed complying with the Dutch National Law on animal experiments, after the approval of the research protocol by the Ethical Committee of LUMC. To evaluate the degradation of the scaffolds for cartilage regeneration in vivo, a total of 7 male C57BL/6Jico 12 weeks old mice were purchased from Charles River, France. Two of them were kept healthy as negative control and 5 were injected with collagenase in the left knee to achieve the chemically induced-OA (Leahy et al., 2015). Non-cell scaffolds ( $1 \mathrm{~mm}^{3}$ cubes) were grafted into five OA mice and two healthy controls, 
and then studied for in vivo stability over 35 days. In brief, mice were operated under $2 \%$ of isoflurane anesthesia and a lateral incision $(\approx 1 \mathrm{~cm})$ was made in the left knee and the joint capsule was exposed longitudinally. The scaffolds were carefully slid into the space of the articular cartilage, then the wound was sutured. The mice were sacrificed at day 35 post-implantation, their hind limbs were removed and studied by fluorescence imaging for signs of scaffold degradation.

Scaffold degradation after implantation in the OA joint. To check the scaffold stability in vivo, NIRF imaging was performed using the IVIS Spectrum animal imaging system (Caliper Life Sciences, Perkin Elmer, Hopkinton, MA), and data analysis was conducted using Living Image 4.3.1 software. Mice were anesthetized with isoflurane balanced with oxygen during image acquisition (less than 1 minute for each imaging session). Sequence images were acquired with the following Excitation/Emission pairs: 710/760 $\mathrm{nm}, 710 / 780 \mathrm{~nm}, 710 / 800,710 / 820 \mathrm{~nm}$ and $710 / 840 \mathrm{~nm}$. Exposure time is auto, FOV $=\mathrm{C}$.

Statistical analysis. All statistical analyses and graphing were performed with OriginPro 2018 software (OriginLab Corp., Northampton, Massachusetts, USA). Data are reported here as mean \pm standard deviation (SD), unless otherwise stated. Error bars represent the SD calculated from test of triplicate measurements for each scaffold. Statistical analysis was evaluated by a one-way analysis of variance (one-way ANOVA) with a $\mathrm{p}<0.05$ to indicate significant differences between samples and marked with an asterisk (or two asterisks, for $\mathrm{p}<0.01$ ).

\section{RESULTS AND DISCUSSION}

\section{Physico-chemical characterization of the scaffolds}

SEM. The morphology of the scaffolds is shown in Figure 1. The low magnification top-view micrograph (Figure 1A) evidenced the scaffold's high level of porosity, promoted by the use of the surfactant Tween 80, and the freeze-drying. Higher magnification (Figure 1B) revealed characteristic details of the materials with a high porosity and the interconnectivity among them. This porous structure favors the uptake of biological fluids (which is discussed in the Swelling Test subsection) and the colonization, attachment, growth and proliferation of cells inside the matrix, shown in Cell viability and In vitro cell attachment and distribution subsections. The pores size was measured using the Image J program (National Institutes of Health, United States), which gave an average size of $169 \pm 8 \mu \mathrm{m}$, that is convenient for the growth and proliferation of chondrocytes inside the scaffold because the size of this type of cell is around $20 \mu \mathrm{m}$ (Errington et al., 1997). 


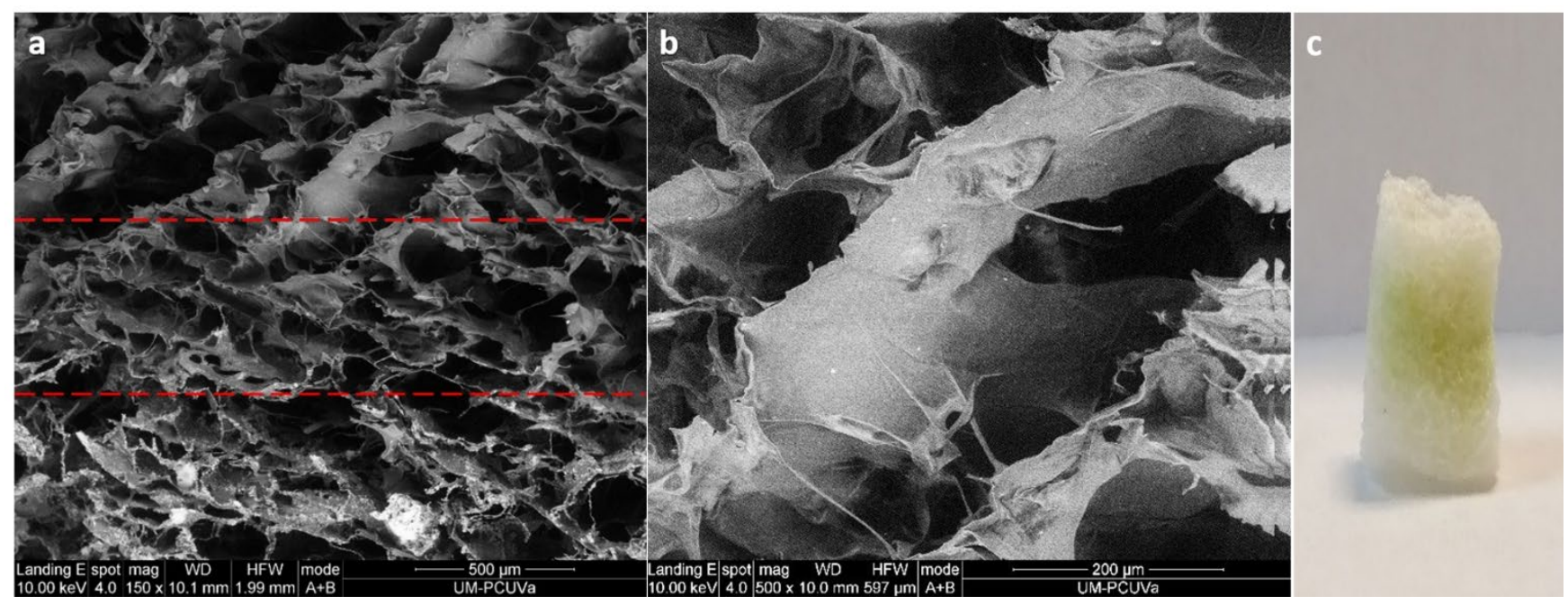

Figure 1. Scanning electron micrographs of the scaffold surface. A) Micrograph at 150X, revealing the high porosity throughout the surface and the homogeneity of the pore size. B) Micrograph at 500X, showing the connections between internal pores. C) Macroscopic pictures of the trilayer scaffold with NIR fluorescence incorporated in the middle layer for in vivo experiments

Micro-CT. The micro-CT images of the scaffold taken in different planes showed the presence of the hydroxyapatite in just one single layer (the layer meant to be placed near subchondral bone), and not in the intermediate or top layers (the red dashed lines mark the borders of the different layers, Figure S2). However, the micro-CT images suggest that a few dispersed hydroxyapatite particles may have migrated during washing of the scaffold.

Rheology. The results of the storage modulus $\left(\mathrm{G}^{\prime}\right)$ and loss modulus $\left(\mathrm{G}^{\prime \prime}\right)$ tests are shown in Figure 2a (in black and gray), revealing that in the scaffold, both parameters are frequency-dependent, as expected. The observed values of $1375 \mathrm{~Pa}$ for $\mathrm{G}^{\prime}$ and $70 \mathrm{~Pa}$ for $\mathrm{G}^{\prime \prime}$, both measured at $1 \mathrm{~Hz}$, correspond approximately to previously reported values (Gonzalez de Torre et al., 2014; Mow et al., 1984).

In the scaffold, the loss factor ( $\tan \delta$; in light gray in Figure 2a, right y-axis), exhibits a slight frequency dependence. The value (calculated at $1 \mathrm{~Hz}$ ) of $\tan \delta$ was $0.05\left(2.86^{\circ}\right)$. As observed in Figure $2 \mathrm{a}$, the phase angles are very small, corresponding to a highly elastic, energy-storing material. Thus, the values for $\mathrm{G}^{\prime}$, $\mathrm{G}^{\prime \prime}$ and $\tan \delta$ are all in the proper range for use in cartilage tissue engineering. The dependence of $\left|\mathrm{G}^{*}\right|$ on $\mathrm{f}^{1 / 2}$ is plotted in Figure $2 \mathrm{~b}$. Two different regions are clearly observed a non-linear one at low frequency $\left(0.01 \mathrm{~Hz}^{1 / 2}\right.$ to $\left.0.30 \mathrm{~Hz}^{1 / 2}\right)$, where intrinsic (fluid-independent) viscoelasticity mechanisms dominate; and a linear one $\left(0.30 \mathrm{~Hz}^{1 / 2}\right.$ to $\left.1.2 \mathrm{~Hz}^{1 / 2}\right)$, in which poroelasticity mechanisms dominate (Gonzalez de Torre et al., 2014). The slope for the linear region was $108 \pm 2 \mathrm{~Pa} / \mathrm{Hz}^{1 / 2}$, similar to that for other materials (Gonzalez de Torre et al., 2014; Vanderhooft et al., 2009). However, at higher frequencies, the linear dependence is lost. 

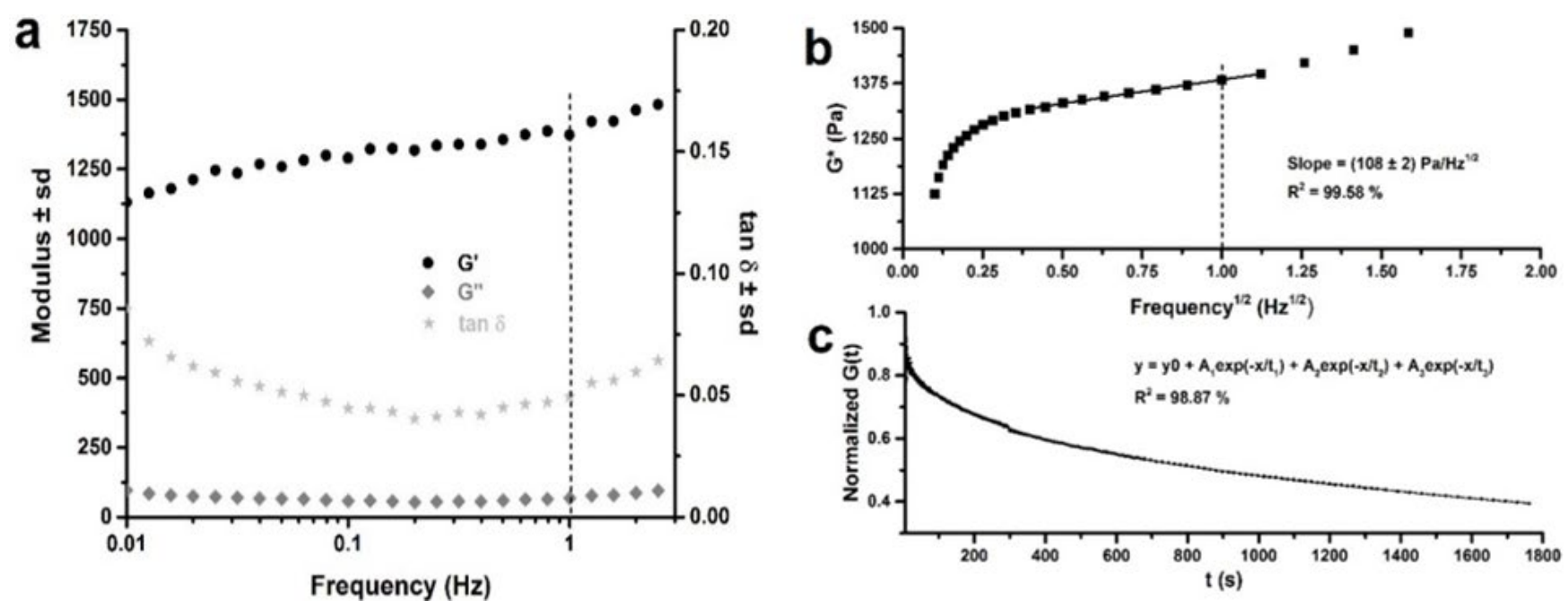

Figure 2. Scaffold rheology properties measured at $0.2 \%$ strain. (a) The storage modulus $\left(G^{\prime}\right)$, the loss modulus $(G$ ') and, to a lesser extent, the loss factor $(\tan \delta$ ) are all frequency dependent. (b) The complex modulus follows two regions: a non-linear one (viscoelasticity) and a linear one (poroelasticity). (c) The time-relaxation modulus $(\mathrm{G}(\mathrm{t}))$ fitted with three relaxation process.

The normalized relaxation modulus transients $[\mathrm{G}(\mathrm{t}) / \mathrm{G}(5 \mathrm{~s})]$ for the scaffold are shown in Figure 2c. They were measured for a strain amplitude of $0.2 \%$ at $37^{\circ} \mathrm{C}$ for all experiments. All the samples were fitted to three relaxation processes $(\mathrm{N}=3)$, which was sufficient to model cartilage behavior under compression. The values obtained for the time-relaxation constants and their corresponding degrees of contribution were $14.6 \mathrm{~s}(0.08), 214.5 \mathrm{~s}(0.17)$ and $2339.9 \mathrm{~s}(0.48)$, and the normalized time-relaxation modulus in the equilibrium was 0.17 . These values suggested that the presence of hydroxyapatite hinder relaxation.

\section{Calcified layer bioactivity in SBF}

Some morphological changes at the scaffold surface were observed by SEM at the different times of immersion in SBF (Figure 3). After 7 days of immersion some apatitic nucleus can be seen on the bottom layer; after 14 days, an appreciable quantity of white apatite nuclei had appeared on the surface; and after 21 days, an apatitic layer had formed on almost the entire surface of the scaffold, thus corroborating its potential for osseointegration with subchondral bone. 

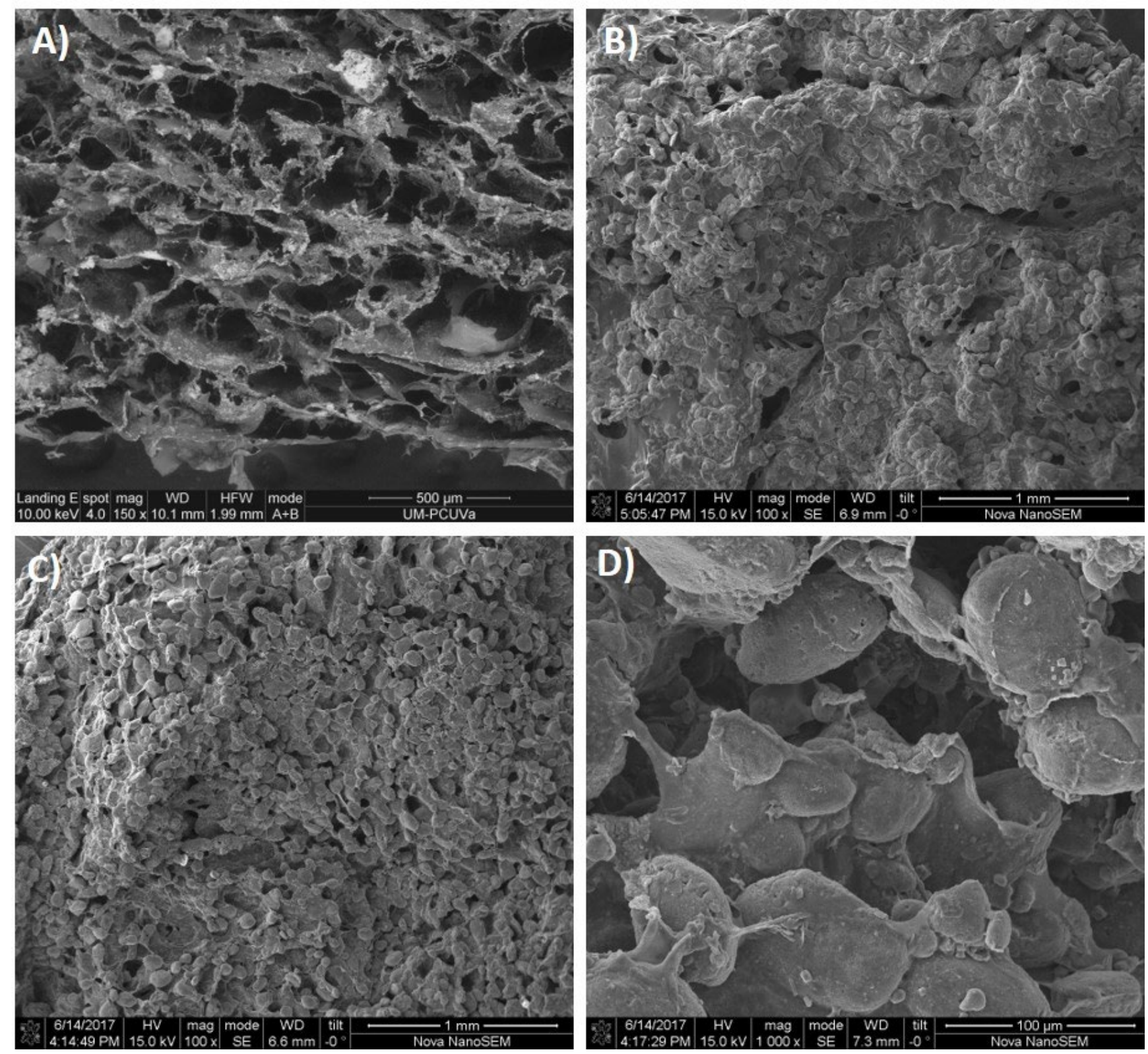

Figure 3. Scanning electron micrographs of scaffold samples after immersion in SBF. A) 0 days (untreated) at $150 \mathrm{X}, \mathrm{B}) 7$ days at $100 \mathrm{X}$ C) 21 days at $100 \mathrm{X}$ and D) 21 days at $1000 \mathrm{X}$.

Swelling test. Adequate swelling of scaffolds is crucial for their practical use in tissue engineering of cartilage regeneration (Khalid et al., 2002). Most natural polymers, like chitosan, readily swell in biological fluids. Some in vitro culture studies have indicated that swelling is favorable, because it provides larger pores in the structure and greater cell attachment and growth in all three dimensions (Vachoud et al., 2000). However, a scaffold must not swell so much that it loses it mechanical integrity and fails. 
In this study, phosphate buffer $(\mathrm{pH}=7.4)$ to match the $\mathrm{pH}$ of the in vitro tests was used. Maximum swelling (1500\%) was reached at $1 \mathrm{~h}$, after which point the weight remains nearly constant (Figure 4A). This higher swelling percent compared to non-porous scaffolds is not only promoted by the hydrophylicity of the polymers, but for the porous structure that allowed the interchange of fluids throw the matrix (Dallan et al., 2007). Figures 4B and 4C show the scaffold before and after 5 hours of immersion in PBS. The scaffold maintained its structure and shape but did swell over time, which may have been due its hydrophilicity. The fact that the scaffold is capable to absorb and retain different fluids suggests that it may offer great versatility for clinical applications (Khalid et al., 2002; Tsai et al., 2007; Vachoud et al., 2000).
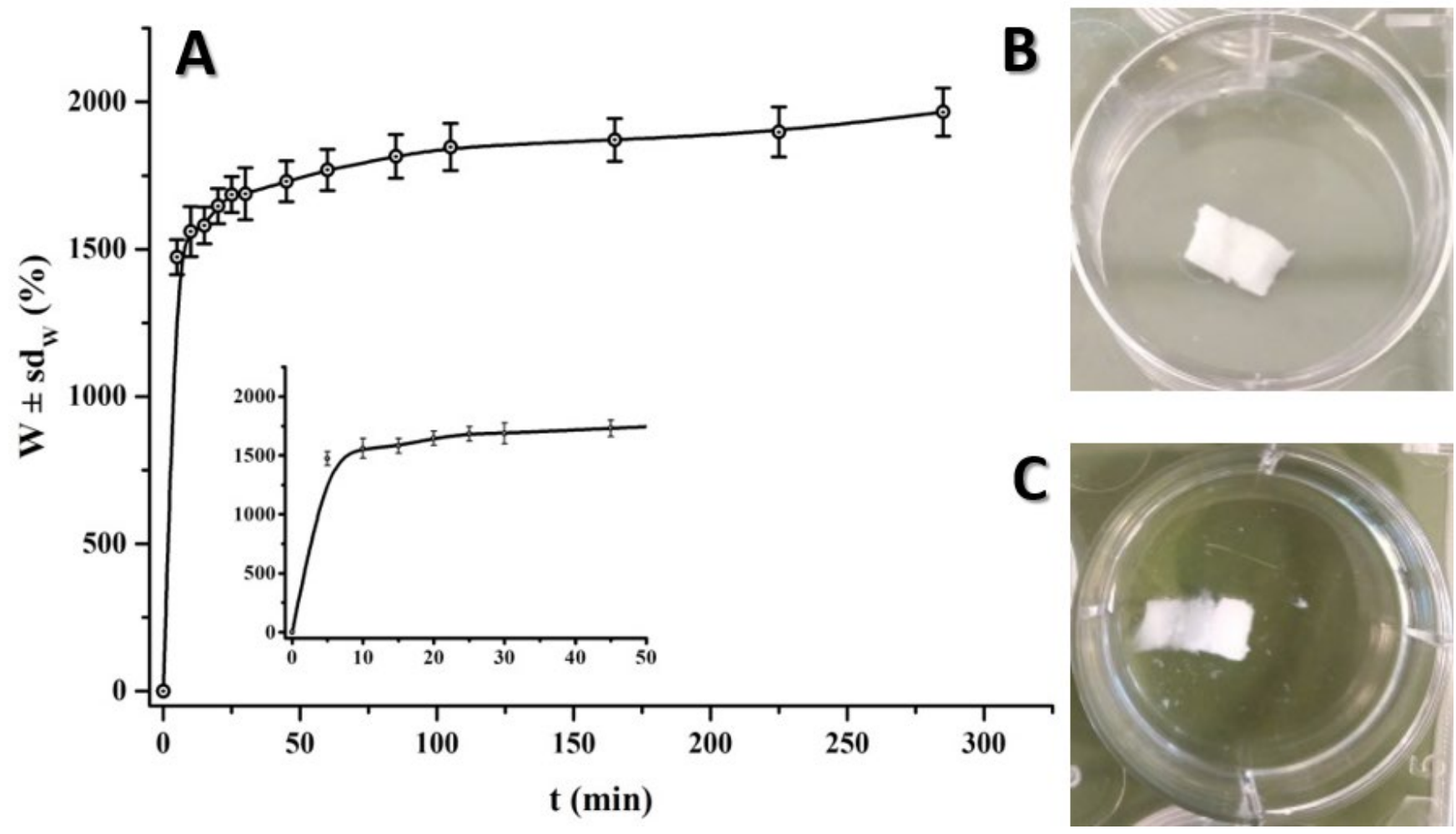

Figure 4. Scaffold water-uptake test. (A) Swelling profile of a scaffold sample immersed in PBS; (B) Photo of a dry scaffold sample; and (C) Photo of a scaffold after maximum swelling, showing retention of original structure. Samples reached equilibrium (i.e. maximum uptake) by 5 hours.

Swelling and degradation of chitosan are based mainly on protonation of its constituent amino and imine groups, and on relaxation of the spiral-shaped chitosan chains. However, in the chitosan/collagen scaffold proposed, protonation of the chitosan amino groups is prevented by their interaction with the collagen carboxyl groups. Accordingly, the chitosan/collagen hybrid degrades more slowly - and thus, is more stable - than pure chitosan. In this study, the scaffold swelling $(1500 \%)$ was fourteen times higher than that previously reported for cross-linked versions of chitosan/collagen hybrid $(135 \%)$ and of plain 
chitosan (108\%), for which the crosslinking agent was EDC/NHS. This behavior may be cause by the fact that the crosslinking agent reduced the number of free amino (and carboxyl) groups available for $\mathrm{H}$ bonding to water molecules, and on the other case with pure chitosan, the authors used a lower percentage of polymer to create their scaffold (Tsai et al., 2007).

In vitro enzymatic degradation. In tissue engineering, the degradation rate of the grafted scaffold at the implant site should be similar to the restoration rate of the local tissue. Accordingly, the speed and mechanism of the biomaterial degradation should be studied. Chitosan is used in numerous tissue engineering applications due to its structural similarity to natural glycosaminoglycan. Collagen is another useful material for these applications, because it is degraded by metalloproteases such as collagenase (Alberts et al., 1994). Since both polymers are degraded enzymatically (Alberts et al., 1994; Lee et al., 1995; TomihataIkada, 1997; Vårum et al., 1996), the speed of the scaffold degradation in situ is dictated by the local concentration of enzymes as well as by the number of available cleavage sites in the scaffold structure (Mann et al., 2001; West \& Hubbell, 1999).
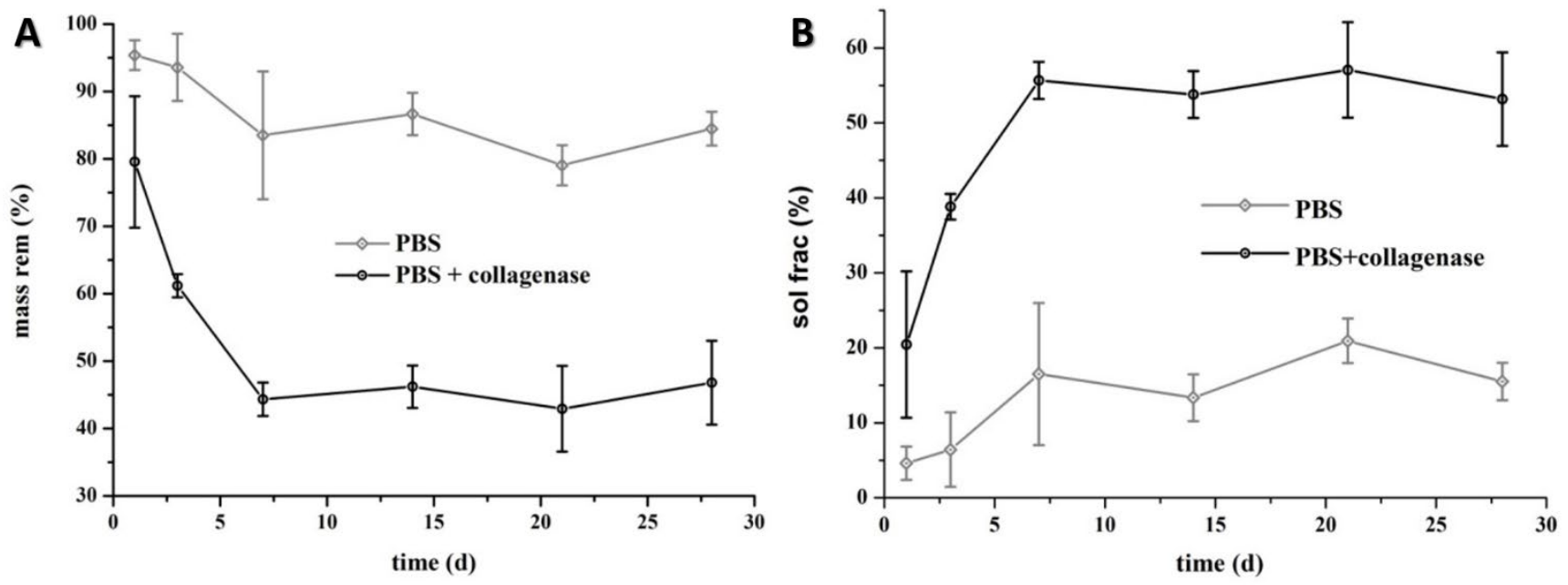

Figure 5. In vitro enzymatic degradation results. Remaining solid (A) and soluble fraction (B) of scaffold samples immersed in either PBS alone (grey) or in a solution of collagenase in PBS (black), expressed as mass percent. Graph (A) reveals that the samples subjected to collagenase treatment lost more mass than those in PBS alone. Graph (B) corroborates the fact that the soluble fraction from the collagenase-treated samples increased more than the soluble fraction from the PBS-treated samples

The results of the in vitro enzymatic degradation test are shown in Figure 5A (remaining mass) and Figure 5B (soluble fraction). Both graphs illustrate a marked difference in degradation between the samples exposed only to PBS, in which approximately $85 \%$ of the mass remained after 30 days $(15 \%$ soluble fraction), and those exposed to collagenase in PBS, of which only approximately $45 \%$ of the mass remained after 30 days (55\% soluble fraction). These data corroborate with the idea that scaffold degradation is down primarily to the presence of collagenase (Ma et al., 2003). Interestingly, the scaffold 
material, which was degraded by $20 \%$ after 24 hours of collagenase treatment, proved to be more stable than another non-crosslinked collagen/chitosan hybrid cited in the literature, which underwent $41.5 \%$ degradation after only 2 hours of collagenase treatment (M. Yang et al., 2000). However, the proposed material was less stable than a collagen/chitosan hybrid crosslinked with glutaraldehyde $(0.25 \%)$, which was degraded by only $26.1 \%$ after 48 hours of collagenase treatment (Ma et al., 2003).

In vitro cell attachment and distribution. To evaluate the potential of the scaffold for tissue engineering cartilage restoration, we assessed its ability to attachment and proliferation of chondrocytes in vitro. The cells attachment was evaluated in two ways: after injecting chondrocytes directly into the center of a scaffold sample, and after seeding them on the top surface of a scaffold sample. In both cases, after 2 hours of contact between the scaffold and the chondrocytes, the cells had become completely attached, which is helped for the porous morphology of the material (Berrier \& Yamada, 2007; Guo et al., 2006) and began to spread over the scaffold's surface and inside the materials. For each sample, all slices of each method were similar to the ones shown in Figure 6 for injection (from A to D) and top seeding (from $\mathrm{E}$ to $\mathrm{H}$ ), respectively. Based on the confocal micrographs, it could be concluded that the top-surface seeding method $(\mathrm{E}-\mathrm{H})$ was superior to the injection method (A-D), as it yielded a higher number and more homogenous distribution of cells in the scaffold.
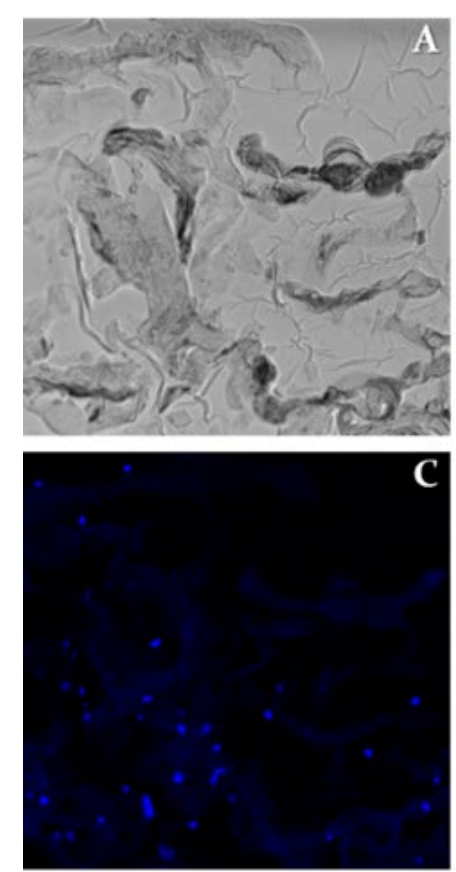
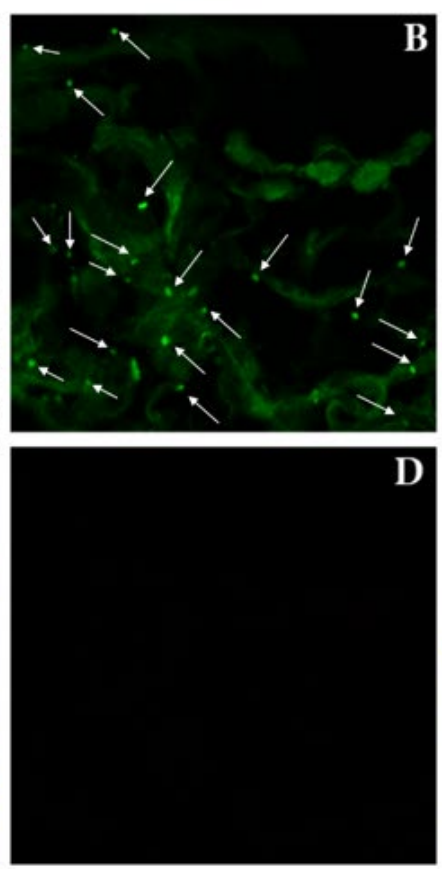
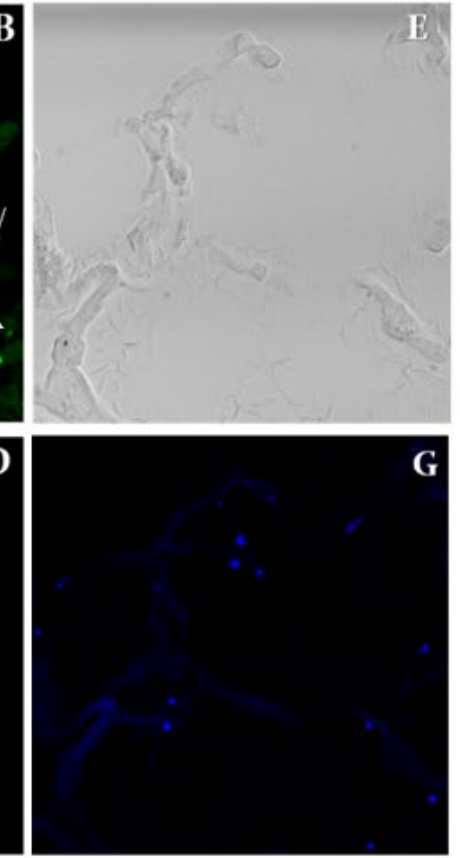
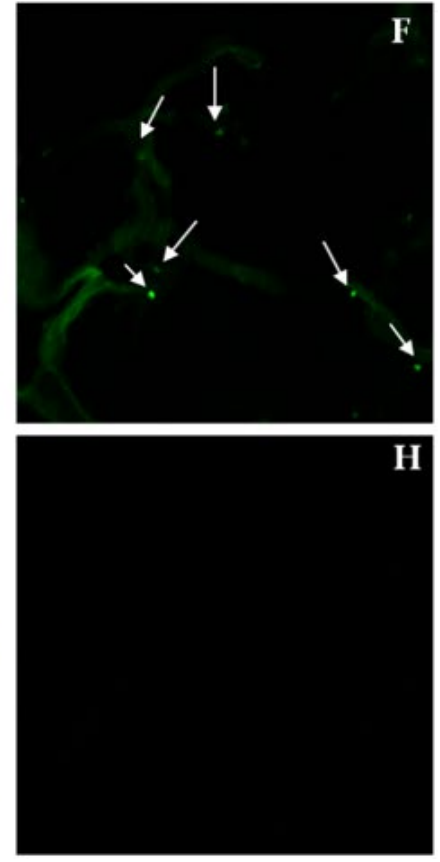

Figure 6. Confocal micrographs of a representative slice of scaffold into which chondrocytes had been injected. (A) Scaffold structure; (B) Living cells, which appear in green; (C) Cells stained with DAPI; and (D) Dead cells, which appear in red. Confocal micrographs of a representative slice of scaffold into which chondrocytes had been seeded on the top of surface. (E) Scaffold structure; (F) Living cells, which appear in green; (G) Cells stained with DAPI; and (H) Dead cells, which appear in red. 
In the scaffold samples into which chondrocytes had been injected, the cells were not concentrated exactly in the centre, but were actually a bit closer to the bottom. We reasoned that they might have moved downwards during attachment, as has previously been reported in cell-injection studies (DvirGinzberg et al., 2003). Thus, the injection method may be viable for seeding cells within a specific area of the scaffold (Vacanti et al., 2001), but does not guarantee a homogeneous distribution of chondrocytes in the material, nor does it yield reproducible experimental results. In contrast, surface-seeding of cells has proven successful in numerous studies, due to its easiness and reproducibility (Choong et al., 2006; Nieponice et al., 2008; Wan et al., 2005). Thus, the results on the superiority of the surface-seeding method over the injection method are consistent with precedent literature.

Cell Viability. LIVE/DEAD ${ }^{\circledR}$ and MTS assays are useful to evaluate the cell viability and proliferation which are very important in tissue engineering and cell-culture studies and several methods to measure these parameters in three-dimensional scaffolds have been developed (Li et al., 2005; Shanmugasundaram et al., 2001). The chondrocyte viability on the scaffolds was studied using the LIVE/DEAD ${ }^{\circledR}$ assay and the MTS assay. In the MTS assay, viability was higher than $70 \%$ at 24 hours of contact between the scaffold and chondrocytes, and gradually increased to reach $90 \%$ at 72 hours (Figure 7A). Thus, based on international guidelines for cytotoxicity (ISO 10933-5), it could be concluded that the scaffold material is not cytotoxic (Aiba, 1991).

Figure 7B shows that at 3 days of incubation, there were living cells in the calcified layer of the material. We attributed this fact to the presence of hydroxyapatite, which promotes cell growth. The dead cells appear as red dots, as does the scaffold material as a continuous structure.

Likewise, Figure 7C illustrates that at 7 days of incubation, the number of living chondrocytes was even higher throughout nearly the whole scaffold. At 10 days, the cells had covered the scaffold (Figure 7E). There were significant differences in cell proliferation at 3 days and 7 days $(95 \% \mathrm{CI})$, and at 7 days and 10 days $(99 \% \mathrm{CI})$. However, there were no significant differences for samples taken at 10 days and those taken at 14 days, suggesting that cell proliferation had slowed down outstandingly by day 10, probably due to the high number of cells already present on the scaffolds that does not allows the further proliferation. 

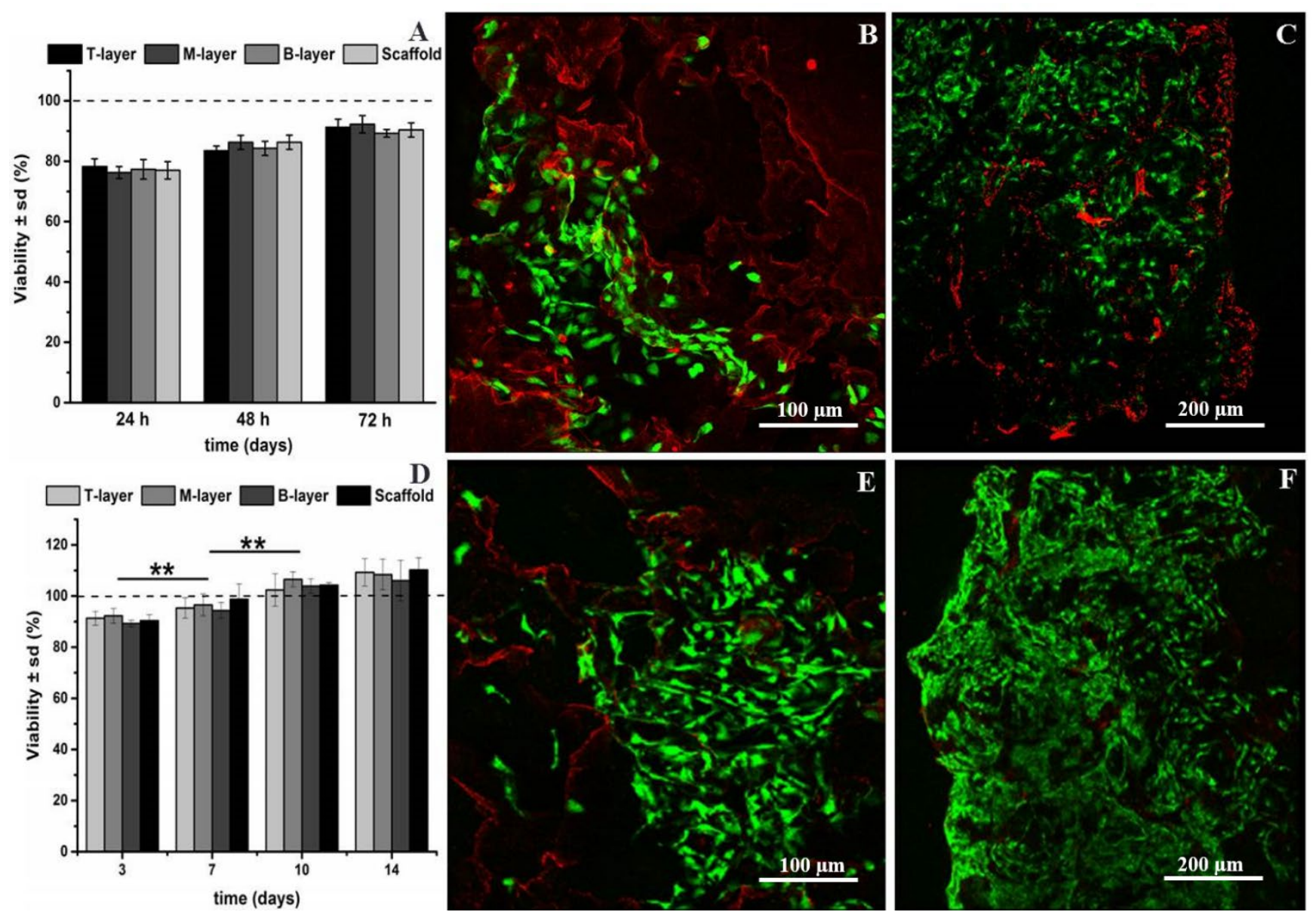

Figure 7. Cell viability assay results. (A) Plot of MTS assay results at 24 hours, 48 hours and 72 hours. Confocal micrographs from the LIVE/DEAD ${ }^{\circledR}$ assay at (B) 3 days, (C) 7 days, (E) 10 days and (F) 14 days of culture. (D) MTS assay to corroborate the LIVE/DEAD ${ }^{\circledR}$ assay results from each time-point.

To corroborate the results of the LIVE/DEAD ${ }^{\circledR}$ assay, MTS assays were performed on samples taken at 3 days, 7 days, 10 days and 14 days. In all cases, cell viability was above $70 \%$ and increased over time, as observed in Figure 7D. During the first days of culture, the chondrocyte growth and proliferation was very fast, and the well was nearly full of cells at 10 days; however, afterwards, it slowed, presumably due to a lack of space inside the well. Together, the above results demonstrate that the porous trilayer scaffold is suitable to growth and proliferate chondrocytes in vitro for at least 14 days. (Khalid et al., 2002; Vachoud et al., 2000, Khalid et al., 2002; Tsai et al., 2007; Vachoud et al., 2000; Tsai et al., 2007; Alberts et al., 1994; Lee et al., 1995; Tomihata \& Ikada, 1997; Vårum et al., 1996; Mann et al., 2001; West \& Hubbell, 1999; Ma et al., 2003; M. Yang et al., 2000; Ma et al., 2003)

Osteogenic potential of the scaffold calcified layer. Osteogenesis is the process of laying down new bone material by osteoblasts. The main purpose or this research is the cartilage tissue regeneration with help of a porous 3D scaffold, but due to this biomaterial will be grafted next to subchondral bone, it is 
necessary to test the osteogenic character of its calcified layer and the cytotoxicity of the biomaterial in osteoblastic cells as well. In this direction, the LIVE/DEAD ${ }^{\circledR}$ assay has been performed seeding osteoblasts onto the scaffold and checked at 3, 7, 10 and 14 days by confocal microscopy. In Figure 8 is clearly seen the considerable increase of the alive osteoblasts population over time, earlier ( 3 and 7 days) in the calcified layer that has hydroxyapatite and later on (10 and 14 days) over the whole material, which demonstrate the osteogenic potential of this calcified layer and the non-cytotoxicity of the $3 \mathrm{D}$ porous scaffold.
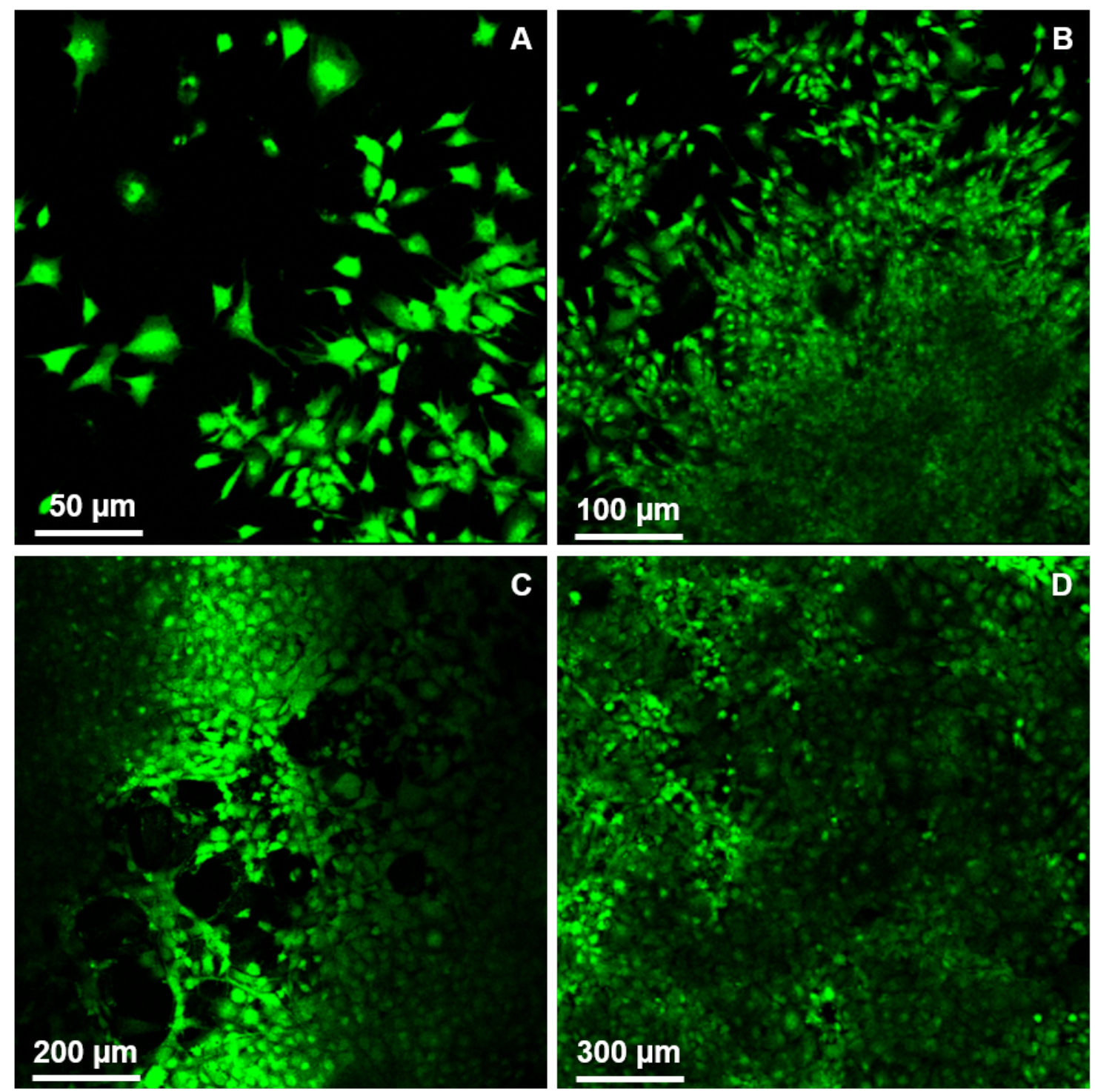

Figure 8. Osteogenic potential of the scaffold calcified layer and cytotoxicity of the material in osteoblasts. Confocal micrographs from the LIVE/DEAD ${ }^{\circledR}$ assay at (A) 3 days, (B) 7 days, (C) 10 days and (D) 14 days of culture.

In vivo degradation study. Although macroscopic fluorescence imaging in the visible range has been 
widely tested with fluorescent proteins, its depth of penetration is limited (only $1 \mathrm{~mm}$ to $2 \mathrm{~mm}$ ) (M. Yang et al., 2000). An interesting alternative is near-infrared (NIR) fluorescence, which can penetrate down to several centimeters (Ntziachristos et al., 2002).

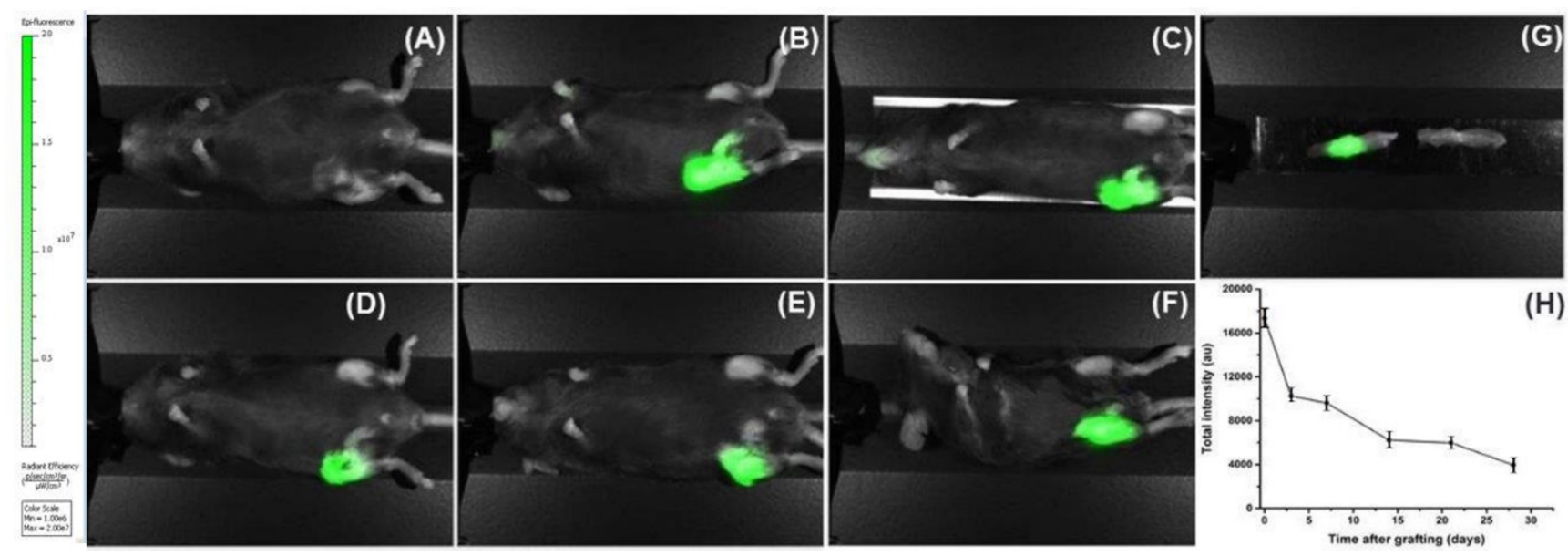

Figure 9. Near infrared (NIR) imaging of a scaffold grafted in the right knee joint of a mouse with chemically induced OA. Images (A) before grafting and at (B) 3 days, (C) 7 days, (D) 15 days, (E) 27 days and (F) 35 days post-grafting. (G) Hind limb extracted after 35 days. (H) Plot of NIR fluorescence intensity over time.

There are numerous recent examples of NIR fluorescence imaging used in vitro and for in vivo animal studies, suggesting its utility for use in diagnosing or treating human diseases (Cowles et al., 2013; Kim et al., 2013). To measure the degradation of scaffolds implanted in the left knee joint of mice with chemically induced osteoarthritis, scaffolds loaded with NIR fluorescence were used (Figure 9). Figures 9B to 9F demonstrate that degradation of the scaffold in vivo was partial and slow, consistent with the results of the in vitro enzymatic degradation test. These results were further corroborated by the NIR fluorescence intensity plot (Figure 9H), which shows a gradual decrease in fluorescence over time. Slow degradation is desirable for tissue engineering scaffolds because, as the scaffold degrades, there is sufficient time for integration of the cells into local tissue and for natural cartilage repair (Kim et al., 2013).

\section{CONCLUSIONS}

An implantable porous trilayer scaffold for cartilage repair has been designed, constructed and tested. It comprises collagen, chitosan and, in one layer, hydroxyapatite as bioactive component. The results from a battery of physicochemical, in vitro and in vivo tests suggest that the scaffold is robust, stable, appropriate to the growth and proliferation of chondrocytes, non-cytotoxic and suitable for in vivo use for at least 5 weeks. However, the search for the ideal scaffold is still ongoing. In this direction, the trilayer scaffold could be improved by incorporating growth factors and a drug capable of inhibiting or decreasing tissue inflammation, before pursuing late preclinical development. 


\section{AUTHOR INFORMATION}

\section{Corresponding Author}

Email: 1.j.cruz_ricondo@lumc.nl

\section{ORCID}

Luis J. Cruz_Ricondo: 0000-0002-0802-1696

\section{Author Contributions}

YC, AA, GF and LJC had full access to all of the data in the study and takes responsibility for the integrity and the accuracy of the data analysis.

YC, AA, GF, FJS and LJC - Study conception and design.

YC, AA, GF, FJS, CE, IQ, AC, EK, YT, LQ, JCRC and LJC - Acquisition of data.

YC, GF, FJS, CE, IQ, YT, LQ, JCRC and LJC - Analysis and interpretation of data.

YC, AA, GF, AC, EK and LJC - First versions writing and final revision of article.

\section{Notes}

There are no conflicts to declare.

\section{Acknowledgements}

The authors would like to acknowledge the financial support from the European Union through the Erasmus PLUS project code NL01-KA 107-008639 for Y. Campos (doctoral fellowship) and G. Fuentes and A. Almirall (staff mobility). G. Fuentes and A. Almirall wish to acknowledge the Matsumae International Foundation for the Research Fellowship and the staff of the Laboratory of Biomaterials, Department of Regeneration Science and Engineering, Institute for Frontier Life and Medical Sciences, Kyoto University, Japan. Also, Luis J. Cruz thanks the financial support of the VIDI personal grant (project number 723.012.110), project grants from the EU Program H2020-MSCA-2015-RISE (644373 - PRISAR) and MSCA-ITN-2015-ETN (675742-ISPIC), H2020-MSCA-ITN-2014 TargetCaRe (642414), H2020-MSCA-2016-RISE (734684 - CHARMED) and H2020-MSCA-RISE-2017 CANCER (777682).

\section{REFERENCES}

Aiba, S. (1991). Studies on chitosan: 3. Evidence for the presence of random and block copolymer structures in partially Nacetylated chitosans. Int J Biol Macromol, 13(1), 40-44. doi:10.1016/0141-8130(91)90008-I

Alberts, B., Bray, D., Lewis, J., et al. (1994). Molecular biology of the cell (3 ${ }^{\text {rd }}$ ed.). New York: Garland Publishing Inc.

Bartels E.M.; Lund H.; Hagen K. B.; Dagfinrud H; Christensen R; Danneskiold-Samsøe, B. Aquatic exercise for the treatment of knee and hip osteoarthritis. Cochrane Database of Systematic Reviews 2007, Issue 4. Art. No.: CD005523. DOI: 10.1002/14651858.CD005523.pub2. 
Bedi, A., Feeley, B. T., \& Williams, R. J. I. (2010). Management of Articular Cartilage Defects of the Knee. The Journal of Bone and Joint Surgery, 92(4), 994-1009. doi:10.2106/jbjs.i.00895

Berrier, A. L., \& Yamada, K. M. (2007). Cell-matrix adhesion. Journal of Cellular Phisiology, 213(3), 565-573.

Blum, J. S., Temenoff, J. S., Park, H., et al. (2004). Development and characterization of enhanced green fluorescent protein and luciferase expressing cell line for non-destructive evaluation of tissue engineering constructs. Biomaterials, 25(27), 5809-5819. doi:10.1016/j.biomaterials.2004.01.035

Choong, C. S. N., Hutmacher, D. W., \& Triffitt, J. T. (2006). Co-culture of Bone Marrow Fibroblasts and Endothelial Cells on Modified Polycaprolactone Substrates for Enhanced Potentials in Bone Tissue Engineering. Tissue Eng, 12(9), 25212531. doi: $10.1089 /$ ten.2006.12.2521

Chung, C. \& Burdick, J. A. (2008). Engineering cartilage tissue. Advanced Drug Delivery Reviews, 60(2), 243-262. doi:10.1016/j.addr.2007.08.027

Clegg, D. O., Reda, D. J., Harris, C. L., et al. (2006). Glucosamine, Chondroitin Sulfate, and the Two in Combination for Painful Knee Osteoarthritis. New England Journal of Medicine, 354(8), 795-808. doi:10.1056/NEJMoa052771

Cowles, E. A., Kovar, J. L., Curtis, E. T., et al. (2013). Near-infrared optical imaging for monitoring the regeneration of osteogenic tissue-engineered constructs. Biores Open Access, 2(3), 186-191. doi:10.1089/biores.2013.0005

Dallan, P. R. M., da Luz Moreira, P., Petinari, L., et al. (2007). Effects of chitosan solution concentration and incorporation of chitin and glycerol on dense chitosan membrane properties. 80(2), 394-405. doi:10.1002/jbm.b.30610

Dvir-Ginzberg, M., Gamlieli-Bonshtein, I., Agbaria, R., et al. (2003). Liver tissue engineering within alginate scaffolds: effects of cell-seeding density on hepatocyte viability, morphology, and function. Tissue Eng, 9(4), 757-766. doi: $\underline{10.1089 / 107632703768247430}$

Errington, R. J., Fricker, M. D., Wood, J. L., Hall, A. C., \& White, N. S. (1997). Four-dimensional imaging of living chondrocytes in cartilage using confocal microscopy: a pragmatic approach. American Journal of Phisiology, 272(3), C1040-C1051.

Goldring, M. B., Birkhead, J. R., Suen, L. F., et al. (1994). Interleukin-1 beta-modulated gene expression in immortalized human chondrocytes. J Clin Invest, 94(6), 2307-2316. doi:10.1172/jci117595

Gonzalez de Torre, I., Santos, M., Quintanilla, L., et al. (2014). Elastin-like recombinamer catalyst-free click gels: characterization of poroelastic and intrinsic viscoelastic properties. Acta Biomaterialia, 10(6), 2495-2505. doi: $\underline{10.1016 / j . a c t b i o .2014 .02 .006}$

Guo, T., Zhao, J., Chang, J., et al. (2006). Porous chitosan-gelatin scaffold containing plasmid DNA encoding transforming growth factor- $\beta 1$ for chondrocytes proliferation. $27(7), 1095-1103$.

Hayami, T. (2008). Osteoarthritis of the knee joint as a cause of musculoskeletal ambulation disability symptom complex (MADS). Clin Calcium, 18(11), 1574-1580. doi:CliCa081115741580

Hench, L. L. (1998). Bioactive materials: the potential for tissue regeneration. J Biomed Mater Res A, 41(4), 511-518. doi:10.1002/(SICI)1097-4636(19980915)41:4<511::AID-JBM1>3.0.CO;2-F

Hochberg, M. C., Altman, R. D., Brandt, K. D., et al. (1995). Guidelines for the medical management of osteoarthritis. Part II. Osteoarthritis of the knee. American College of Rheumatology. Arthritis Rheum, 38(11), 1541-1546. doi: $\underline{10.1002 / \text { art.1780381103 }}$

Hofmann, A., Konrad, L., Gotzen, L., et al. (2003). Bioengineered human bone tissue using autogenous osteoblasts cultured on different biomatrices. J Biomed Mater Res A, 67(1), 191-199. doi:10.1002/jbm.a.10594

Honda, M. J., Yada, T., Ueda, M., et al. (2004). Cartilage formation by serial passaged cultured chondrocytes in a new scaffold: hybrid 75:25 poly(L-lactide-epsilon-caprolactone) sponge. J Oral Maxillofac Surg, 62(12), 1510-1516. doi:10.1016/j.joms.2003.12.042

Hunziker, E. B. (2002). Articular cartilage repair: basic science and clinical progress. A review of the current status and prospects. Osteoarthritis and cartilage, 10(6), 432-463. doi:10.1053/joca.2002.0801

Khalid, M. N., Agnely, F., Yagoubi, N., et al. (2002). Water state characterization, swelling behavior, thermal and mechanical properties of chitosan based networks. European Journal of Pharmaceutical Sciences, 15(5), 425-432. 


\section{doi:10.1016/S0928-0987(02)00029-5}

Kim, S. H., Lee, J. H., Hyun, H., et al. (2013). Near-Infrared Fluorescence Imaging for Noninvasive Trafficking of Scaffold Degradation. Nature Scientific Reports, 3, 1198-1204. doi:10.1038/srep01198

Kokubo, T. (1991). Bioactive glass ceramics: properties and applications. Biomaterials, 12(2), 155-163. doi:10.1016/01429612(91)90194-F

Kokubo, T., \& Takadama, H. (2006). How useful is SBF in predicting in vivo bone bioactivity? Biomaterials, 27(15), 29072915. doi:10.1016/j.biomaterials.2006.01.017

Kon, E., Mandelbaum, B., Buda, R., et al. (2011). Platelet-Rich Plasma Intra-Articular Injection Versus Hyaluronic Acid Viscosupplementation as Treatments for Cartilage Pathology: From Early Degeneration to Osteoarthritis. Arthroscopy: The Journal of Arthroscopic \& Related Surgery, 27(11), 1490-1501. doi:10.1016/j.arthro.2011.05.011

Leahy, A. A., Esfahani, S. A., Foote, A. T., et al. (2015). Analysis of the trajectory of osteoarthritis development in a mouse model by serial near-infrared fluorescence imaging of matrix metalloproteinase activities. Arthritis \& Rheumatology, 67(2), 442-453. doi: $10.1002 /$ art.38957

Lee, K. Y., Ha, W. S., \& Park, W. H. (1995). Blood compatibility and biodegradability of partially N-acylated chitosan derivatives. Biomaterials, 16(16), 1211-1216. doi:10.1016/0142-9612(95)98126-Y

Li, Z., Ramay, H. R., Hauch, K. D., et al. (2005). Chitosan-alginate hybrid scaffolds for bone tissue engineering. Biomaterials, 26(18), 3919-3928. doi:10.1016/j.biomaterials.2004.09.062

Ma, L., Gao, C., Mao, Z., et al. (2003). Collagen/chitosan porous scaffolds with improved biostability for skin tissue engineering. Biomaterials, 24(26), 4833-4841. doi:10.1016/S0142-9612(03)00374-0

Mann, B. K., Gobin, A. S., Tsai, A. T., et al. (2001). Smooth muscle cell growth in photopolymerized hydrogels with cell adhesive and proteolytically degradable domains: synthetic ECM analogs for tissue engineering. Biomaterials, 22(22), 3045-3051. doi:10.1016/S0142-9612(01)00051-5

Mow, V. C., Holmes, M. H., \& Lai, W. M. (1984). Fluid transport and mechanical properties of articular cartilage: a review. Journal of biomechanics, 17(5), 377-394. doi:10.1016/0021-9290(84)90031-9

Neo, M., Kotani, S., Nakamura, T., et al. (1992). A comparative study of ultrastructures of the interfaces between four kinds of surface-active ceramic and bone. Journal of Biomedical Materials Research Part A, 26(11), 1419-1432. doi: $10.1002 / \mathrm{jbm} .820261103$

Niemeyer, P., Krause, U., Fellenberg, J., et al. (2004). Evaluation of mineralized collagen and alpha-tricalcium phosphate as scaffolds for tissue engineering of bone using human mesenchymal stem cells. Cells Tissues Organs, 177(2), 68-78. doi: $10.1159 / 000079182$

Nieponice, A., Soletti, L., Guan, J., et al. (2008). Development of a tissue-engineered vascular graft combining a biodegradable scaffold, muscle-derived stem cells and a rotational vacuum seeding technique. Biomaterials, 29(7), 825833. doi:10.1016/j.biomaterials.2007.10.044

Ntziachristos, V., Ripoll, J., \& Weissleder, R. (2002). Would near infrared fluorescence signals propagate through large human organs for clinical studies. Optics Letters, 27(5), 527-529. doi:10.1364/OL.27.000333

O'Brien, F. J., Harley, B. A., Yannas, I. V., et al. (2005). The effect of pore size on cell adhesion in collagen-GAG scaffolds. Biomaterials, 26(4), 433-441. doi:10.1016/j.biomaterials.2004.02.052

Østergaard, M., \& Halberg, P. (1998). Intra-Articular Corticosteroids in Arthritic Disease. BioDrugs, 9(2), 95-103. doi:10.2165/00063030-199809020-00002

Ripamonti, U. (1996). Osteoinduction in porous hydroxyapatite implanted in heterotopic sites of different animal models. Biomaterials, 17(1), 31-35. doi:10.1016/0142-9612(96)80752-6

Secretan, C., Bagnall, K. M., \& Jomha, N. M. (2010). Effects of introducing cultured human chondrocytes into a human articular cartilage explant model. Cell and tissue research, 339(2), 421-427. doi:10.1007/s00441-009-0901-Z

Shanmugasundaram, N., Ravichandran, P., Neelakanta Reddy, P., et al. (2001). Collagen-chitosan polymeric scaffolds for the in vitro culture of human epidermoid carcinoma cells. Biomaterials, 22(14), 1943-1951. doi:10.1016/S0142$\underline{9612(00) 00220-9}$ 
Ślósarczyk, A., Paszkiewicz, Z., \& Paluszkiewicz, C. (2005). FTIR and XRD evaluation of carbonated hydroxyapatite powders synthesized by wet methods. Journal of Molecular Structure, 744-747, 657-661. doi: $10.1016 /$ j.molstruc.2004.11.078

Tawakoli, P. N., Al-Ahmad, A., Hoth-Hannig, W., et al. (2013). Comparison of different live/dead stainings for detection and quantification of adherent microorganisms in the initial oral biofilm. Clinical Oral Investigations, 17(3), 841-850. doi:10.1007/s00784-012-0792-3

Thier, S., Weiss, C., \& Fickert, S. (2017). Arthroscopic autologous chondrocyte implantation in the hip for the treatment of full-thickness cartilage defects: A case series of 29 patients and review of the literature. SICOT-J, 3, 72-81. doi: $10.1051 / \operatorname{sicotj} / 2017037$

Tomihata, K., \& Ikada, Y. (1997). In vitro and in vivo degradation of films of chitin and its deacetylated derivatives. Biomaterials, 18(7), 567-575. doi:10.1016/S0142-9612(96)00167-6

Tsai, S.-P., Hsieh, C.-Y., Hsieh, C.-Y., et al. (2007). Preparation and cell compatibility evaluation of chitosan/collagen composite scaffolds using amino acids as crosslinking bridges. Journal of Applied Polymer Science, 105(4), 1774-1785. doi:10.1002/app. 26157

Vacanti, C. A., Bonassar, L. J., Vacanti, M. P., et al. (2001). Replacement of an Avulsed Phalanx with Tissue-Engineered Bone. New England Journal of Medicine, 344(20), 1511-1514. doi:10.1056/nejm200105173442004

Vachoud, L., Zydowicz, N., \& Domard, A. (2000). Physicochemical behaviour of chitin gels. Carbohydrate Research, 326(4), 295-304. doi:10.1016/S0008-6215(00)00038-0

Vanderhooft, J. L., Alcoutlabi, M., Magda, J. J., et al. (2009). Rheological properties of cross-linked hyaluronan-gelatin hydrogels for tissue engineering. Macromol Biosciences, 9(1), 20-28 doi:10.1002/mabi.200800141

van der Horst, G., van Bezooijen, R. L., Deckers, M. M. L., et al. (2002). Differentiation of murine preosteoblastic KS483 cells depends on autocrine bone morphogenetic protein signaling during all phases of osteoblast formation. Bone, 31(6), 661-669. doi: $10.1016 / \mathrm{S} 8756-3282(02) 00903-1$

Vårum, K. M., Kristiansen Holme, H., Izume, M., et al (1996). Determination of enzymatic hydrolysis specificity of partially N-acetylated chitosans. Biochimica et Biophysica Acta (BBA) - General Subjects, 1291(1), 5-15. doi:10.1016/0304-4165(96)00038-4

Wan, Y., Wang, Y., Liu, Z., et al. (2005). Adhesion and proliferation of OCT-1 osteoblast-like cells on micro- and nanoscale topography structured poly(L-lactide). Biomaterials, 26(21), 4453-4459. doi:10.1016/j.biomaterials.2004.11.016

West, J. L., \& Hubbell, J. A. (1999). Polymeric biomaterials with degradation sites for proteases involved in cell migration. Macromolecules, 32(1), 241-244. doi:10.1021/ma981296k

Yang, M., Baranov, E., \& Jiang, P. (2000). Whole-body optical imaging of green fluorescent protein-expressing tumors and metastases. Proceedings of the USA National Academy of Sciences, 97(3), 1206-1211. doi:10.1073/pnas.97.3.1206

Yang, Z., Yuan, H., Tong, W., et al. (1996). Osteogenesis in extraskeletally implanted porous calcium phosphate ceramics: variability among different kinds of animals. Biomaterials, 17(22), 2131-2137. doi:10.1016/0142-9612(96)00044-0

Yuan, H., De Bruijn, J. D., Li, Y., et al. (2001). Bone formation induced by calcium phosphate ceramics in soft tissue of dogs: a comparative study between porous alpha-TCP and beta-TCP. Journal of Materials Science: Materials in Medicine, 12(1), 7-13. doi:10.1023/A:1026792615665

Yuan, H., Li, Y., De Bruijn, J., et al (2000). Tissue responses of calcium phosphate cement: a study in dogs. Biomaterials, 2l(12), 1283-1290. doi:10.1016/S0142-9612(00)00016-8

Zhang, W., Moskowitz, R. W., Nuki, G., et al. (2008). OARSI recommendations for the management of hip and knee osteoarthritis, Part II: OARSI evidence-based, expert consensus guidelines. Osteoarthritis and cartilage, 16(2), 137162. doi:10.1016/j.joca.2007.12.013 